Article

\title{
Time-Dependent Behavior of a Circular Symmetrical Tunnel Supported with Rockbolts
}

\author{
Wei Han ${ }^{1}$, Gang Wang ${ }^{1,2, *}$, Chuanzheng Liu ${ }^{3}{ }^{(1)}$, Hengjie Luan ${ }^{2}$ (D) and Ke Wang ${ }^{1}$ \\ 1 Shandong Provincial Key Laboratory of Civil Engineering Disaster Prevention and Mitigation, Shandong \\ University of Science and Technology, Qingdao 266590, China; sdkdhwei@163.com (W.H.); \\ sdwangke1115@163.com (K.W.) \\ 2 State Key Laboratory of Mining Disaster Prevention and Control Co-Founded by Shandong Province and \\ the Ministry of Science and Technology, Shandong University of Science and Technology, Qingdao 266590, \\ China; luanjie0330@126.com \\ 3 School of Environment and Resource, Southwest University of Science and Technology, Mianyang 621000, \\ China; lcuanzeng@yeah.net \\ * Correspondence: wanggang1110@gmail.com; Tel.: +86-159-5488-4373
}

Received: 19 July 2018; Accepted: 28 August 2018; Published: 4 September 2018

\begin{abstract}
Under the effect of initial stress and excavation disturbance, there exists interaction between rock mass and rockbolt in deeply buried tunnels. In order to fully explore the mechanism of rock mass supported with rockbolts, this article studied the time-dependent behavior of the rock mass supported with discretely mechanically or frictionally coupled (DMFC) rockbolts. The interaction model elastic solutions under distributed force model were analyzed, then the viscoelastic analytical solutions were conducted to describe the rheological properties of the coupling model, and the solutions were acquired by setting the constitutive models of the rockbolt and rock mass in terms of a one-dimensional Kelvin model and a three-dimensional Burgers model based on material properties and dimension. Several examples were performed and the influence of initial stress $\sigma_{0}$, the viscosity parameters $\eta_{1}$ and $\eta_{2}$ of the three-dimensional Burgers model as well as the pre-tension $T_{0}$ on reinforcement effect were analyzed. According to the proposed model, the smaller $\eta_{2}$ is or the larger the pre-tension $T_{0}$ is, the more effective the support effect. However, when the pre-tension is too large, the support effect is no longer significantly enhanced. In addition, the early reinforcement effect is controlled by the first creep stage in the Burgers model while the ultimate support effect is mainly influenced by the viscosity coefficient of the second creep stage in the Burgers model. This research can provide an important theoretical reference to guide the parameter design of rockbolt reinforcement engineering in a circular symmetrical tunnel.
\end{abstract}

Keywords: time-dependent behavior; rockbolt support; viscoelastic solutions; circular symmetrical tunnel

\section{Introduction}

Rockbolts have been extensively employed for rock reinforcement in civil and mining engineering for many years [1]. However, the interaction mechanism between rockbolt and rockmass is still not clear at present [2]. Some engineering materials have certain rheological characteristics [3]. Due to the time-dependent behavior of the material, the rock mass displacement and stress may increase after excavation, and may last for several months or years [4]. Understanding the rheological mechanism of rock mass supported with rockbolts is essential for engineering design optimization.

Various approaches have been established to describe the time-dependent behavior of rock mass or rockbolt based on analytical solutions [5-7], empirical approaches [8-10], and numerical 
methods [11-13]. Li et al. [14] studied the effect of the stress, creep coefficient, and geometry parameters on the stress relaxation of rockbolts. However, the time-dependence of rock mass was ignored. Wang et al. [15] presented the viscoelastic solutions of the coupling model with a distributed force model through using several common rheological models, since the selected rheological model does not consider material properties and dimensional effects. Therefore, it cannot fully reflect the true rheological behavior of the coupling model. Sharifzadeh et al. [16] simulated the long-term deformation of a tunnel excavated in a weak rock mass, and noted that the instability of the tunnel may be attributed to the stress induced by the creep behavior of the surrounding rock. Above-research have primarily been focused on the evolution of rock mass or rockbolt, few studies have been conducted on the coupling rheological behavior of the interaction model [15].

The research work in this paper is to study the coupling rheological behavior of the rock mass supported with discretely mechanically or frictionally coupled (DMFC) rockbolts based on reasonable rheological model and dimension. The elastic and viscoelasticity solutions were first discussed, and the parametric study was subsequently conducted. Finally, the long-term tunnel stability was evaluated.

\section{Coupling Mechanical Model of the Rockbolt and Rock Mass System}

\subsection{Principle of the Coupling Model}

The rockmass would deform under the initial stress and support force of the rockbolt. Here, we assumed that the rockbolt-rock mass will not be decoupled, so the deformation of the rockbolt is coordinated with the rock mass, and the coupling process is depicted in Figure 1.

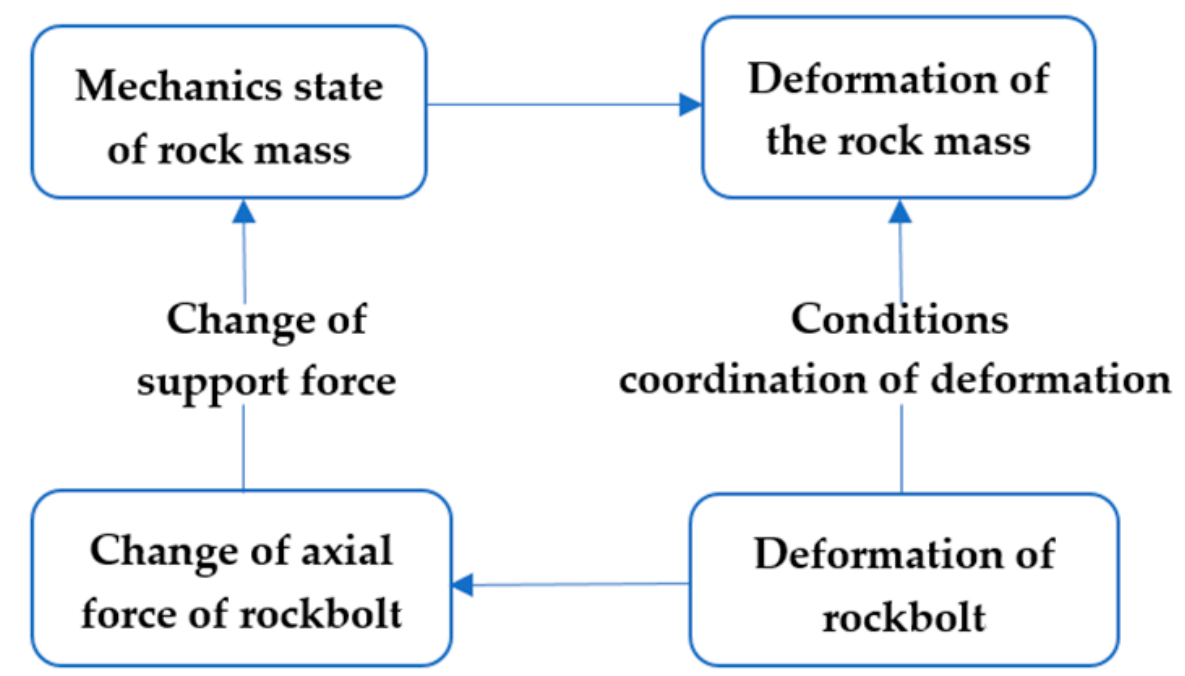

Figure 1. Coupling process of rockbolt and rock mass.

The reinforcement mechanism for DMFC rockbolts can be divided into three models: the distribution force model, the point load model, and the equivalent material model. Distribution force models regard the force of the rockbolt to rock mass as the tangential uniform distribution of the surface force. The point load model simplifies a circular tunnel as a spring device, which reduces the force to a pair of opposing forces of equal magnitude. The equivalent material model divides the rock mass into a reinforced and an original zone. The rock mass and rockbolt in the reinforced area are regarded as homogeneous media. However, the equivalent material model neglects the mechanism of the action between the rockbolt and the rock mass in the reinforced zone; thus it cannot reflect the true rheological state of the rockbolt and rock mass. This paper employs the distribution force calculation considering the analytic complexity of the point load model and the hypothesis error of the equivalent material model. The distributions of the three models are shown in Figure 2. 


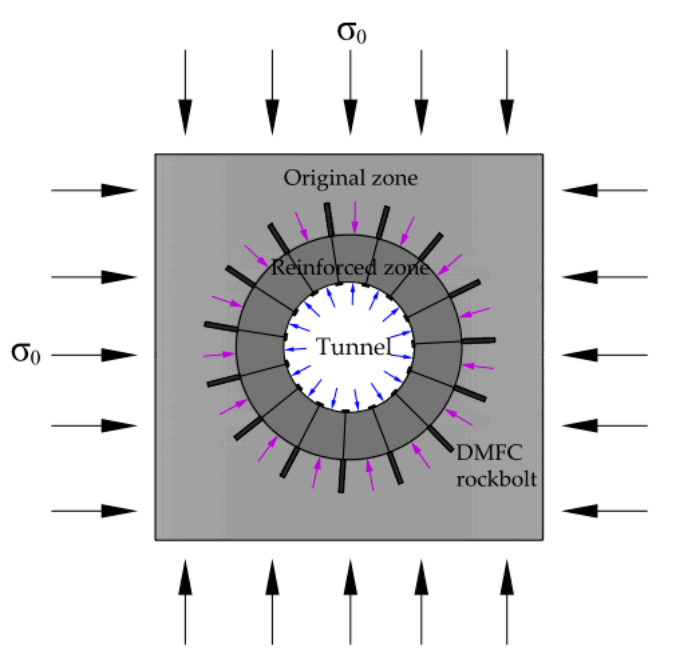

(a)

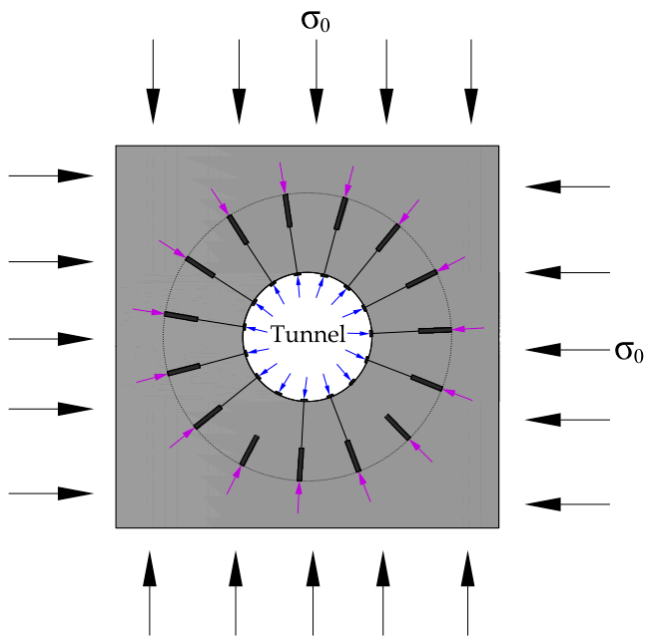

(b)

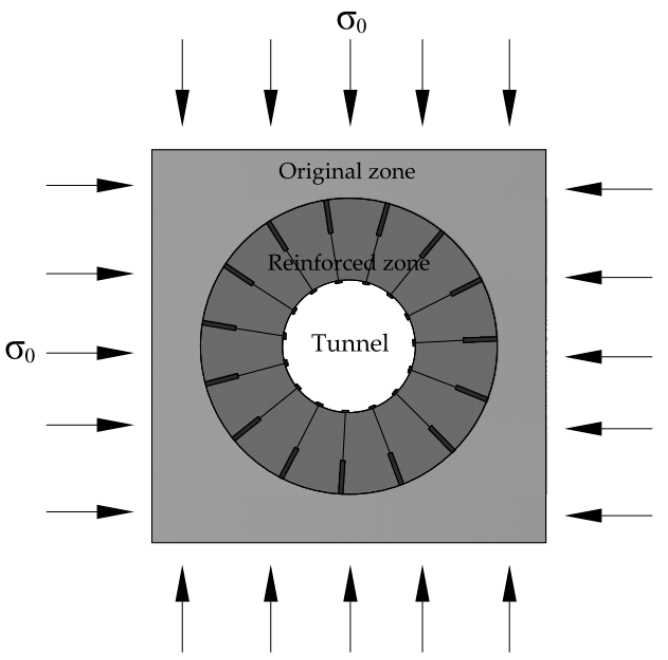

(c)

Figure 2. Three main analytical models of DMFC rockbolts: (a) distributed force model; (b) point load model; (c) equivalent material model.

\subsection{Elastic Solutions}

The relative distributions of the rockbolts and rock mass is shown in Figure 3. The following assumptions are taken: (a) the tunnel is circular and deep; (b) the support force in tunnel opening $P_{0}$ and the reinforcement force $P_{\rho}$ are uniformly distributed on the excavation surface and the interface between the reinforced zone and the original zone; (c) the problem is axisymmetric, and the lateral pressure coefficient $K_{a}=1$; and (d) the deformation is small.

For the axisymmetric problem under polar coordinates, the general stress formula and displacement formulae can be expressed as:

$$
\begin{gathered}
\sigma_{\rho}=\frac{A}{\rho^{2}}+B(1+2 \ln \rho)+2 C \\
\sigma_{\theta}=-\frac{A}{\rho^{2}}+B(1+2 \ln \rho)+2 C \\
u_{\rho}=\frac{1}{E}\left(-(1+\mu) \frac{A}{\rho}+(1-3 \mu) B \rho+2\right. \\
(1-\mu) B \rho(\ln \rho-1)+2(1-\mu) C \rho)
\end{gathered}
$$


where $\sigma_{\rho}, \sigma_{\theta}$ and $u_{\rho}$ are respectively the radial stress, tangential stress and displacement; $E$ is Young's modulus; $\mu$ is Poisson's ratio; $\rho$ is the radial coordinate; $A, B$, and $C$ are coefficients.

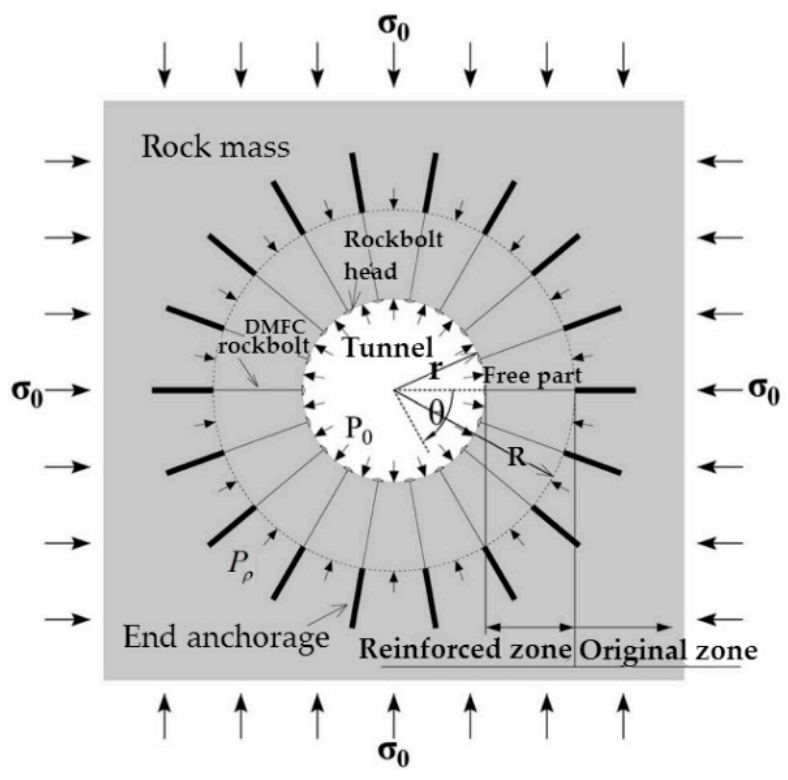

Figure 3. Geometric model with DMFC rockbolt in a circular symmetrical tunnel.

When the tunnel is not excavated, the displacement elastic solution of the rock mass under the initial stress is as follows:

$$
u_{\rho}^{0}=\frac{1+\mu}{E_{r}}(1-2 \mu) \sigma_{0} \rho
$$

In the reinforced zone, the mechanical problem can be regarded in terms of the elastic mechanics of the rear wall cylinder under internal and external pressure: the internal force arises from the support of the rockbolt. A mechanical analysis diagram is shown in Figure $4 \mathrm{~b}$. The general forms expressions for the stress and displacement in the reinforcement zone $(r<\rho<R)$ can be written as:

$$
\begin{gathered}
\sigma_{\rho 1}=\frac{A_{1}}{\rho^{2}}+2 C_{1} \\
\sigma_{\theta 1}=-\frac{A_{1}}{\rho^{2}}+2 C_{1} \\
u_{\rho 1}=\frac{1+\mu}{E_{r}}\left[2(1-2 \mu) C_{1} \rho-\frac{A_{1}}{\rho}\right]
\end{gathered}
$$

where $\sigma_{\rho 1}, \sigma_{\theta 1}$ and $u_{\rho 1}$ are respectively the radial stress, tangential stress, and displacement in the reinforced zone and $A_{1}$ and $C_{1}$ are the pending coefficients.

In the original zone, the mechanical problem can be regarded in terms of the elastic mechanics of an infinite region affected by the initial stress $\sigma_{0}$ and pressure on the inside of a circular hole. A mechanical analysis diagram is shown in Figure $4 a$. The general forms expressions of the stress and displacement in the original zone $(\rho>R)$ are as follows:

$$
\begin{gathered}
\sigma_{\rho 2}=\frac{A^{\prime}}{\rho^{2}}+2 C^{\prime} \\
\sigma_{\theta 2}=-\frac{A^{\prime}}{\rho^{2}}+2 C^{\prime}
\end{gathered}
$$




$$
u_{\rho 2}=\frac{1+\mu}{E_{r}}\left[2(1-2 \mu) C^{\prime} \rho-\frac{A^{\prime}}{\rho}\right]
$$

where $\sigma_{\rho 2}, \sigma_{\theta 2}$ and $u_{\rho 2}$ are respectively the radial stress, tangential stress, and displacement in the original zone, and $A^{\prime}$ and $C^{\prime}$ are coefficients.

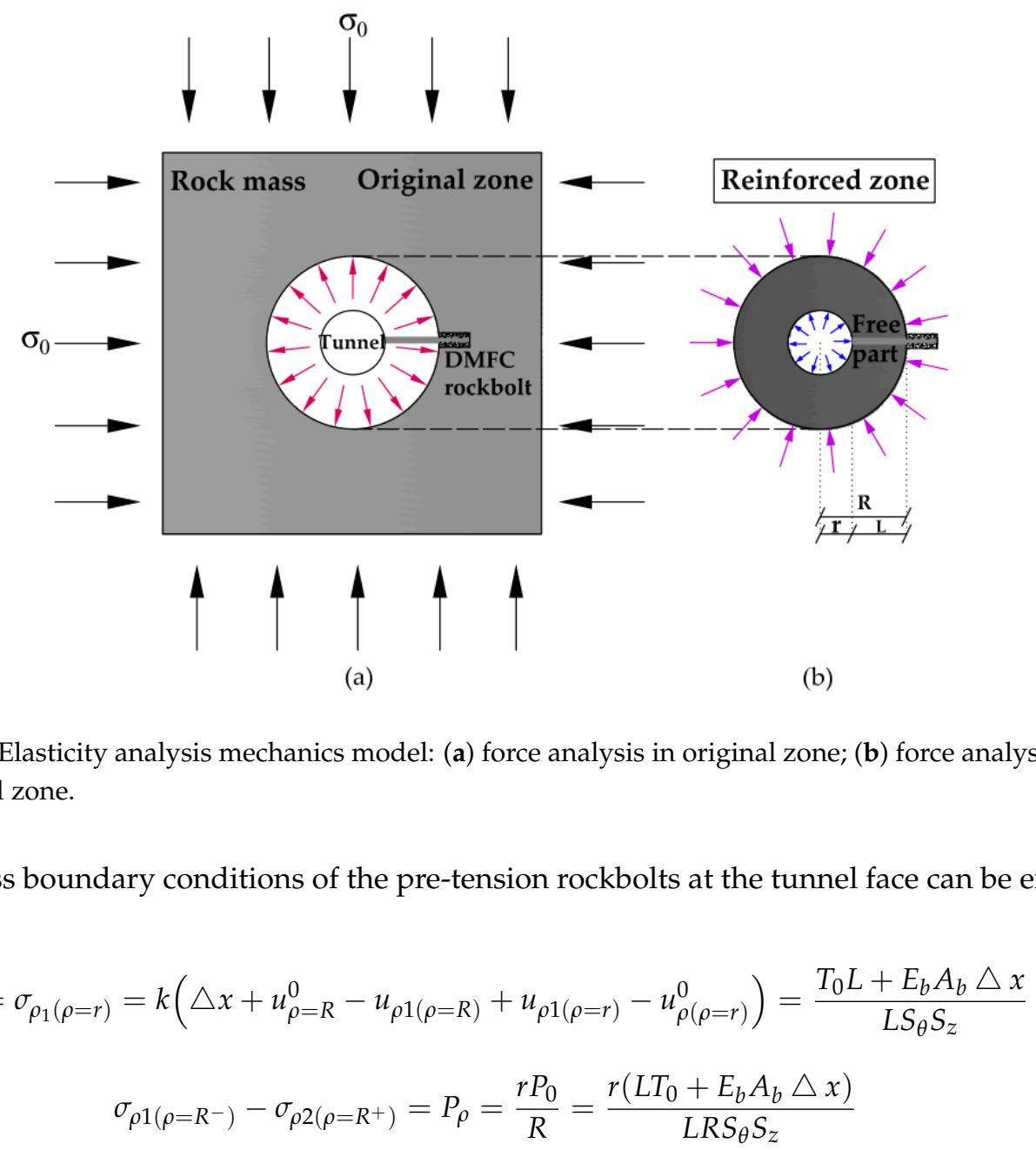

where $P_{0}$ is the support force in tunnel opening; $P_{\rho}$ is the reinforcement force; $L$ is the length of the free part of the rockbolt; $\triangle L$ is the deformation of the rockbolt in the axial direction, $\Delta x$ is the pre-tension length of the rockbolt; $S_{Z}$ is the rockbolt spacing in the longitudinal direction; $S_{\theta}$ is the rockbolt spacing in the tangential direction; $u_{\rho 1(\rho=R)}^{0}$ and $u_{\rho 1(\rho=r)}^{0}$ are the displacements of the original state without support; $A_{b}$ is the area of the rockbolt cross section; and $E_{b}$ is the elastic modulus of the rockbolt.

The other boundary conditions can be expressed as follows:

$$
\begin{gathered}
u_{\rho 1(\rho=r)}=u_{\text {rockbolt }, \rho(\rho=r)} \\
u_{\rho 2(\rho=R)}=u_{\text {rockbolt }, \rho(\rho=R)} \\
u_{\rho 1\left(\rho=R^{-}\right)}=u_{\rho 2\left(\rho=R^{+}\right)} \\
\sigma_{\rho(\rho \rightarrow \infty)}=\sigma_{0}
\end{gathered}
$$

The elastic solutions of the rockbolt and rock mass can be presented by combining the displacement and stress conditions. Solutions have been discussed [17-20]. 


\subsection{Viscoelastic Solutions}

Wang et al. [15] selected several common rheological models to explain the rheological characteristic of rockbolts and rock masses; the Maxwell and the Kelvin model are respectively used to describe the rheological properties of the rockbolts and rock masses in this paper. While the Maxwell model cannot characterize the elastic after-effect and deformation limit characteristics of rock mass, the Kelvin model cannot characterize the transient and viscous flow of a rock mass. However, in practical engineering, the rock mass will have transient deformation and viscous flow due to the disturbance of excavation [3]. Therefore, there may be some drawbacks in fully expressing the rheology of a rock mass based on the selected models. Choosing a rheological model that is more consistent with the material properties to reflect the time-dependency of the rockbolt-rock mass coupling model fully is necessary.

\subsubsection{Rheological Model of Rockbolt and Definition of Operator Function}

With respect to the material properties, the rockbolt is primarily composed of a hot rolled ribbed bar, the amount of creep for steel is small, and the creep of the steel is dominated by stable creep. With respect to the scale effect, the axial stiffness of the rockbolt is much greater than the tangential stiffness, and the rockbolt can be regarded as an ideal one-dimensional viscoelastic material. Based on the analysis of the rheological properties of the steel bar, this paper uses a one-dimensional Kelvin model to describe the rheological properties of the rockbolt.

The variation between the viscoelasticity and the one-dimensional elastic parameters of the rockbolt is shown in Equation (8), where $Q_{b}(D)$ and $P_{b}(D)$ are the operator functions of the one-dimensional Kelvin rheological model. The space parameter transformation based on the Laplace transform is

$$
E_{b}=\frac{Q_{b}(D)}{P_{b}(D)} \stackrel{\text { Laplace transform }}{\longrightarrow} \overline{E_{b}}(s)=\frac{{\overline{Q_{b K}}}^{\prime}(s)}{{\overline{P_{b K}}}^{\prime}(s)}
$$

The Laplace form of the one-dimensional Kelvin model operator is

$$
\begin{gathered}
{\overline{P_{b K}}}^{\prime}(s)=1 \\
{\overline{Q_{b K}}}^{\prime}(s)=E_{b}+\eta_{b} s
\end{gathered}
$$

where $\eta_{b}$ is the rockbolt's viscosity coefficient, $s$ is the variable obtained from the Laplace transformation.

\subsubsection{Rheological Model of Rock Mass and Definition of Operator Function}

With respect to the material properties, the characteristics of the rock mass are complicated and changeable in underground engineering. The Burgers model consists of the Maxwell model and the Kelvin model; the model can describe rheological properties such as elastic deformation, creep, stress relaxation, elastic effect and viscous flow. With respect to the scale effect, the size of one direction is much longer than the other two directions for some engineering fields, the problem should be considered as three-dimensional problem [21]. In tunnel engineering, the excavation direction is substantially longer than the other two directions; thus, the rock mass should be regarded as a three-dimensional viscoelastic material. The one-dimensional constitutive equation needs to be extended to a three-dimensional form, and the three-dimensional viscoelastic constitutive relation can be derived from the corresponding relation of the one-dimensional viscoelastic constitutive relation. The distribution of rheological model diagram is shown in Figure 5. 


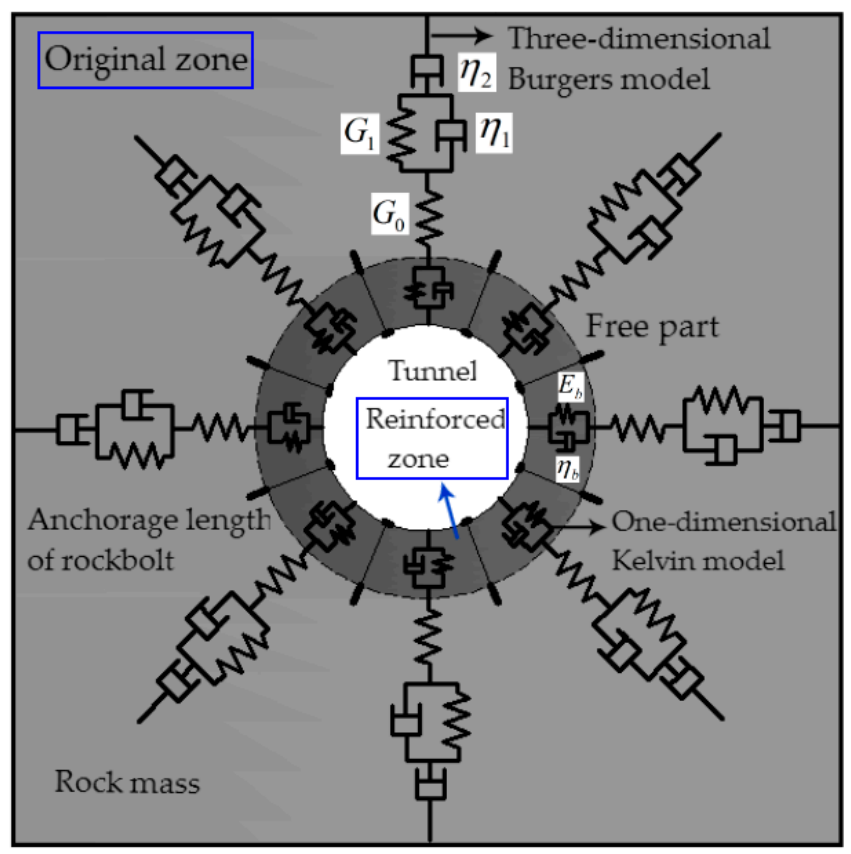

Figure 5. Schematic of the rheological model distribution.

For the rock mass, the three-dimensional viscoelastic constitutive equation can be obtained by developing the one-dimensional constitutive equation based on the generalized Hooke's law

$$
\sigma_{i j}=2 G_{0} e_{i j}+K \varepsilon_{i j} \delta_{i j}
$$

The relationships among the shear modulus, bulk modulus, Young's modulus, and Poisson's ratio $\mu$ are

$$
\begin{gathered}
E_{r}=\frac{9 G_{0} K}{3 K+G_{0}} \\
\mu=\frac{3 K-2 G_{0}}{2\left(3 K+G_{0}\right)}
\end{gathered}
$$

Therefore, the constitutive models of the elastic and viscoelastic materials can be written as

$$
\begin{gathered}
S_{i j}=2 G_{0} e_{i j}=2 \frac{Q^{\prime}(D)}{P^{\prime}(D)} e_{i j} \\
\sigma_{i j}=3 K \varepsilon_{i j}=3 \frac{Q^{\prime \prime}(D)}{P^{\prime \prime}(D)} \varepsilon_{i j}
\end{gathered}
$$

where $S_{i j}$ is the partial stress tensor; $e_{i j}$ is the partial strain tensor; $\sigma_{i j}$ is the stress tensor; $\varepsilon_{i j}$ is the strain tensor; and $Q^{\prime}(D), P^{\prime}(D), Q^{\prime \prime}(D)$ and $P^{\prime \prime}(D)$ are the operator functions of the rock mass viscoelastic constitutive model.

The transformation expressions of the elastic parameters and viscoelasticity parameters are expressed as

$$
\begin{aligned}
& \bar{E}(s)=\frac{9 \bar{Q}^{\prime}(s) \bar{Q}^{\prime \prime}(s)}{3 \bar{P}^{\prime}(s) \bar{Q}^{\prime \prime}(s)+\bar{P}^{\prime \prime}(s) \bar{Q}^{\prime}(s)} \\
& \bar{\mu}_{s}=\frac{3 \bar{P}^{\prime}(s) \bar{Q}^{\prime \prime}(s)-2 \bar{P}^{\prime \prime}(s) \bar{Q}^{\prime}(s)}{2\left[3 \bar{P}^{\prime}(s) \bar{Q}^{\prime \prime}(s)+\bar{P}^{\prime \prime}(s) \bar{Q}^{\prime}(s)\right]}
\end{aligned}
$$


where $s$ is the Laplace variable, and the operator functions of the Laplace space form in three-dimensional Burgers model can be expressed as

$$
\begin{gathered}
\bar{P}^{\prime}(s)=1+\left(\frac{\eta_{2}}{G_{0}}+\frac{\eta_{1}+\eta_{2}}{G_{1}}\right) s+\frac{\eta_{1} \eta_{2}}{G_{0} G_{1}} s^{2} \\
\bar{Q}^{\prime}(s)=\eta_{2} s+\frac{\eta_{1} \eta_{2}}{G_{1}} s^{2} \\
\bar{P}^{\prime \prime}(s)=1 \\
\bar{Q}^{\prime \prime}(s)=K
\end{gathered}
$$

where $\eta_{1}$ is the viscous coefficient of the first creep stage; $\eta_{2}$ is the viscous coefficient of the second creep stage; $G_{0}$ is the elastic shear modulus of the rock mass; $G_{1}$ is the corresponding viscoelastic shear modulus of the rock mass; and $K$ is the elastic bulk modulus of the rock mass.

The Laplace space solutions can be obtained by replacing the elastic parameters of the elastic solutions with the viscoelastic parameters and substituting the Laplace operator function of the selected rheological model, which enables the viscoelastic problem to be solved. The viscoelastic solution can be obtained by the Laplace inverse.

The parameters of the elastic solutions are replaced by viscoelastic parameters and substituted into the operator functions of the corresponding rheological model. The main process is expressed as follows

$$
\begin{gathered}
E_{r} \stackrel{\text { replaced by }}{\longrightarrow} \frac{9 \bar{Q}^{\prime}(s) \bar{Q}^{\prime \prime}(s)}{3 \bar{P}^{\prime}(s) \bar{Q}^{\prime \prime}(s)+\bar{P}^{\prime \prime}(s) \bar{Q}^{\prime}(s)} \\
\mu \stackrel{\text { replaced by }}{\longrightarrow} \frac{3 \bar{P}^{\prime}(s) \bar{Q}^{\prime \prime}(s)-2 \bar{P}^{\prime \prime}(s) \bar{Q}^{\prime}(s)}{2\left[3 \bar{P}^{\prime}(s) \bar{Q}^{\prime \prime}(s)+\bar{P}^{\prime \prime}(s) \bar{Q}^{\prime}(s)\right]} \\
k \stackrel{\text { replaced by }}{\longrightarrow} \frac{A_{b}}{S_{\theta} S_{z} L} \frac{\overline{Q_{b K}}(s)}{{\overline{P_{b K}}}^{\prime}(s)}
\end{gathered}
$$

\subsection{Analytical Solutions in the Laplace Space}

The Laplace space analytical solutions can be described by substituting in the operator function of the corresponding rheological model, and the stress and displacement fields of the rock mass are expressed in Appendix A (A1)-(A6).

Then, the tunnel surface support stress can be calculated as follows

$$
\begin{aligned}
P_{0} & =\frac{\left(T_{0}+\frac{E_{b} A_{b} \Delta x}{L}\right)_{\text {rockbolt }}=\frac{A_{b}}{S_{\theta} S_{\theta} S_{z}}{\overline{\bar{Q}_{b K}}}^{\prime}(s)}{P_{b K}^{\prime}(s)} \varepsilon_{\text {rockbolt }} \\
& =\frac{A_{b}}{S_{\theta} S_{z}} \frac{{\overline{Q_{b K}}}^{\prime}(s)}{\frac{P_{b K}}{P_{b K}}(s)} \frac{\Delta x}{L}=k \cdot \Delta x=k \cdot\left[\lim _{\rho \rightarrow R^{+}} u_{\rho 2 s}-\lim _{\rho \rightarrow r^{-}} u_{\rho 1 s}\right]
\end{aligned}
$$

Therefore, the axial force of the rockbolt can be written as

$$
T=\frac{A_{b}{\overline{Q_{b K}}}^{\prime}(s)\left[\lim _{\rho \rightarrow R^{+}} u_{\rho 2 s}-\lim _{\rho \rightarrow r^{-}} u_{\rho 1 s}\right]}{L{\overline{P_{b K}}}^{\prime}(s)}
$$

where the tensioned rockbolt deformation is $\triangle x=\frac{T_{0} L}{E_{b} A_{b}}$. Hence, the axial force of rockbolt can be expressed in Appendix A (A7). 


\section{Analysis of the Analytical Solution Using Engineering Parameters}

\subsection{Axial Force Changes over Time}

The corresponding parameter values are provided in Table 1. The analytical curves can be obtained by substituting the parameters into the corresponding expression and performing the inverse Laplace transformation.

Table 1. Imputing parameters of rockbolt and rockmass.

\begin{tabular}{ccccccccc}
\hline Parameters & Case $\mathbf{1}$ & Case 2 & Case 3 & Case 4 & Case $\mathbf{5}$ & Case $\mathbf{6}$ & Case 7 & Case 8 \\
\hline$R / \mathrm{m}$ & 8 & 8 & 8 & 8 & 8 & 8 & 8 & 8 \\
$r / \mathrm{m}$ & 4 & 4 & 4 & 4 & 4 & 4 & 4 & 4 \\
$A_{b} / 10^{-4} \mathrm{~m}^{2}$ & 3.0 & 3.0 & 3.0 & 3.0 & 3.0 & 3.0 & 3.0 & 3.0 \\
$E_{b} / 10^{11} \mathrm{~Pa}$ & 2.0 & 2.0 & 2.0 & 2.0 & 2.0 & 2.0 & 2.0 & 2.0 \\
$L / \mathrm{m}$ & 4.0 & 4.0 & 4.0 & 4.0 & 4.0 & 4.0 & 4.0 & 4.0 \\
$K / 10^{9} \mathrm{~Pa}$ & 2.2 & 2.2 & 2.2 & 2.2 & 2.2 & 2.2 & 2.2 & 2.2 \\
$G_{0} / 10^{9} \mathrm{~Pa}$ & 1.5 & 1.5 & 1.5 & 1.5 & 1.5 & 1.5 & 1.5 & 1.5 \\
$G_{1} / 10^{10} \mathrm{~Pa}$ & 6.0 & 6.0 & 6.0 & 6.0 & 6.0 & 6.0 & 6.0 & 6.0 \\
$\eta_{b} / 10^{20} \mathrm{~Pa} \cdot \mathrm{s}$ & 3.0 & 3.0 & 3.0 & 3.0 & 3.0 & 3.0 & 3.0 & 3.0 \\
$\eta_{1} / 10^{10} \mathrm{~Pa} \cdot \mathrm{s}$ & 5.0 & 3.0 & 7.0 & 5.0 & 5.0 & 5.0 & 5.0 & 5.0 \\
$\eta_{2} / 10^{11} \mathrm{~Pa} \cdot \mathrm{s}$ & 2.0 & 2.0 & 2.0 & 4.0 & 6.0 & 2.0 & 2.0 & 2.0 \\
$T_{0} / 10^{4} \mathrm{~N}$ & 4.0 & 4.0 & 4.0 & 4.0 & 4.0 & 5.0 & 5.5 & 4.0 \\
$\sigma_{0} / 10^{6} \mathrm{~Pa}$ & -2.0 & -2.0 & -2.0 & -2.0 & -2.0 & -2.0 & -2.0 & -3.0 \\
\hline
\end{tabular}

As shown in Figure $6 \mathrm{a}$, the influences of $\eta_{1}$ and $\sigma_{0}$ on the axial force evolve over time. The results indicate that $\eta_{1}$ affects not only the axial force initial value but also the rockbolt rheological state. When $\eta_{1}=3.0 \times 10^{10}$ and $5.0 \times 10^{10} \mathrm{~Pa} \cdot \mathrm{s}$, the axial force decreases to a stable value over time, the rockbolt rheological state is stress relaxation. When $\eta_{1}=7.0 \times 10^{10} \mathrm{~Pa} \cdot \mathrm{s}$, the axial force increases to a stable value over time, the rheological state of the rockbolt is stable creep. The axial force will converge to a stable value regardless of whether the rheological state of a rockbolt is creep or stress relaxation; thus $\eta_{1}$ does not affect the stable value of the axial force and only influences the early support effect. When $\eta_{1}$ and $\eta_{2}$ remain unchanged, a larger $\sigma_{0}$ will generate a larger initial force and higher stability. Figure $6 \mathrm{~b}$ indicates that the influences of $\eta_{2}$ and $\sigma_{0}$ on the axial force evolve over time. The results indicate that $\eta_{2}$ affects not only the initial value and stable value of axial force but also the rheological state of the rockbolt; thus, $\eta_{2}$ affects not only the early reinforced effect but also the final support effect. When $\eta_{2}=1.0 \times 10^{11} \mathrm{~Pa} \cdot \mathrm{s}, 1.5 \times 10^{11} \mathrm{~Pa} \cdot \mathrm{s}$, and $2.0 \times 10^{11} \mathrm{~Pa} \cdot \mathrm{s}$, the axial force decreases to a stable value over time; thus, the rheological state of the rockbolt is stress relaxation. A smaller value of $\eta_{2}$ produces a larger initial value and convergent value of the axial force. When $\eta_{2}=3.0 \times 10^{11} \mathrm{~Pa} \cdot \mathrm{s}$, the axial force increases to a stable value over time, and the convergent value is less than $\eta_{2}=1.0 \times 10^{11} \mathrm{~Pa} \cdot \mathrm{s}, 1.5 \times 10^{11} \mathrm{~Pa} \cdot \mathrm{s}$, and $2.0 \times 10^{11} \mathrm{~Pa} \cdot \mathrm{s}$; thus, the rheological state of the rockbolt is creep. As shown in Figure $6 c$, the influence of $\eta_{b}$ on axial force evolves over time. When $\eta_{b}=1.0 \times 10^{20} \mathrm{~Pa} \cdot \mathrm{s}$ and $3.0 \times 10^{20} \mathrm{~Pa} \cdot \mathrm{s}$, the axial force decreases to a stable value over time, the rockbolt rheological state is stress relaxation. When $\eta_{b}=5.0 \times 10^{20} \mathrm{~Pa} \cdot \mathrm{s}$, the axial force is gradually reduced to zero and then increases to a stable value over time; the stable value is the same as when $\eta_{b}=1.0 \times 10^{20} \mathrm{~Pa} \cdot \mathrm{s}$ and $3.0 \times 10^{20} \mathrm{~Pa} \cdot \mathrm{s}$. When $\eta_{b}=6.0 \times 10^{20} \mathrm{~Pa} \cdot \mathrm{s}$, the axial force of the rockbolt increases to a stable value over time; thus, the rockbolt rheological state is creep, and the initial value is the same as when $\eta_{1}=3.0 \times 10^{10} \mathrm{~Pa} \cdot \mathrm{s}$. Figure $6 \mathrm{~d}$ reveals that the influence of $T_{0}$ on the axial force evolves over time; larger values of $T_{0}$ produce a greater absolute value of initial axial force. Thus, the larger is $T_{0}$, the better the support effect. When $T_{0}=4.0 \times 10^{4} \mathrm{~N}, 5.0 \times 10^{4} \mathrm{~N}$, and $5.5 \times 10^{4} \mathrm{~N}$, the axial force absolute value gradually decreases over time and converges to a fixed value. A larger value of $T_{0}$ yields a higher fix value. But, when the $T_{0}$ is too large, the fix value will not increase significantly. At this time, the rockbolt support to the rock mass is in the stage of relaxation. 


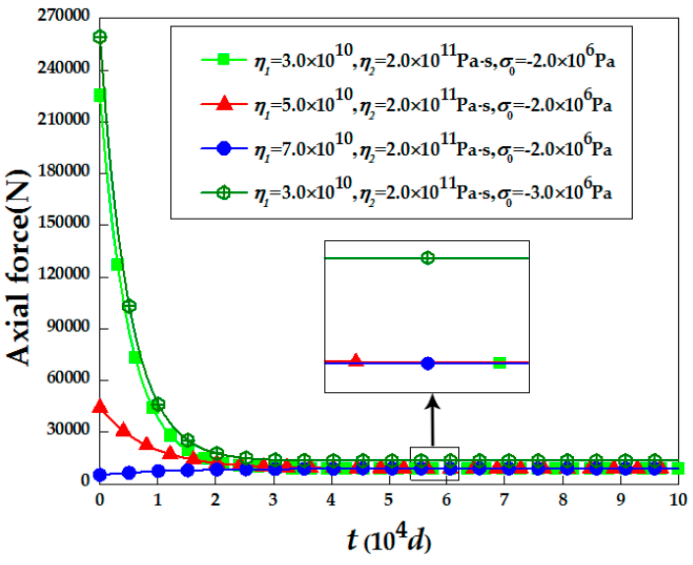

(a)

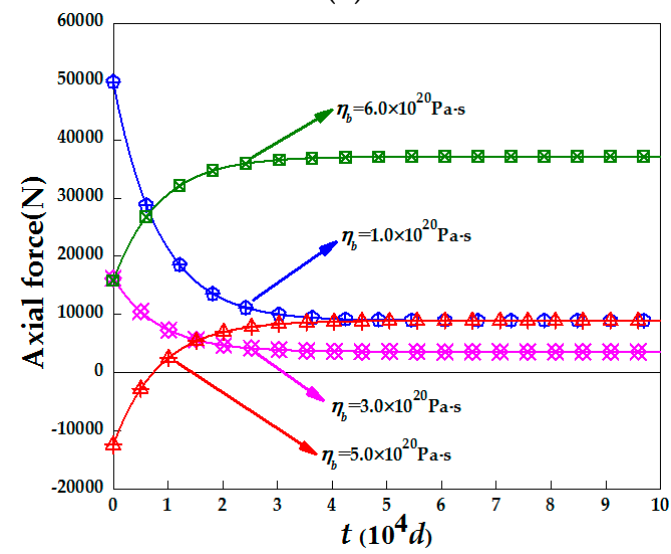

(c)

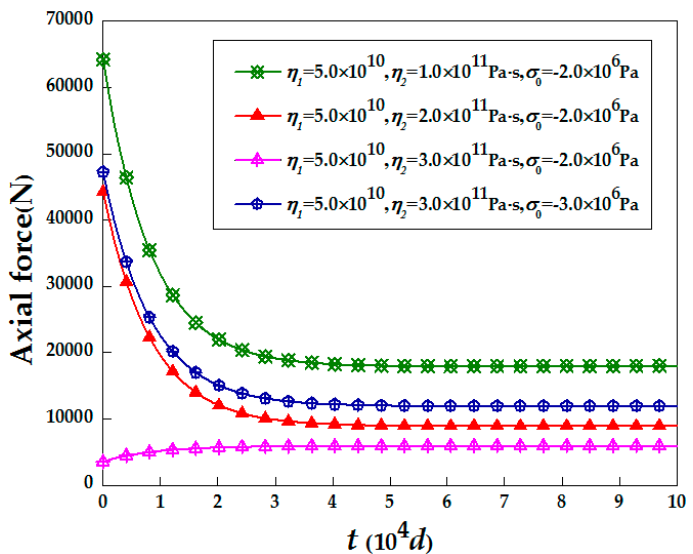

(b)

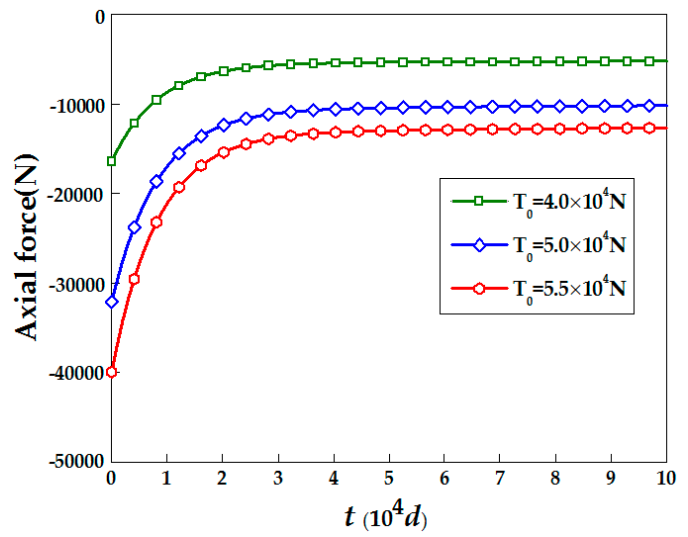

(d)

Figure 6. Evolution of the axial force over time: (a) influences of $\eta_{1}$ and $\sigma_{0}$ on the axial force over time; (b) influence of $\eta_{2}$ on the bolt axial force over time; (c) influence of $\eta_{b}$ on the axial force over time; and (d) influence of $T_{0}$ on the axial force over time.

\subsection{Radial Stress Changes over Time}

As shown in Figure 7, the case considered in this test primarily investigated how the viscosity coefficients $\eta_{1}, \eta_{2}$ and $\sigma_{0}$ influenced the radial stress. Figure 7 a shows the jump value fitting curve between the reinforced and the original zone when the time is zero. When $\eta_{2}$ is fixed, the fitting curve is $y_{1}=-4334.5 \times x+49929 . R^{2}=0.9198$. When $\eta_{1}$ is fixed, the fitting curve is $y_{2}=-1160.3 \times x+27924$. $R^{2}=0.9513$. As shown in Figure $7 \mathrm{a}, \eta_{1}$ and $\eta_{2}$ are negatively correlated with the radial stress jump value, and the slope of $y_{1}$ is greater than the slope of $y_{2}$, which indicates that the effect of $\eta_{1}$ on the radial stress jump value is larger than the effect of $\eta_{2}$. The radial stress jumps at the junction of the reinforced zone and the original zone due to the support of the rockbolt. Figure $7 \mathrm{~b}$ shows the radial stress fitting curve in the excavation surface when the time is zero; when $\eta_{2}$ is fixed, the fitting curve is $y_{3}=-19850 \times x+214942 . R^{2}=0.936$. When $\eta_{1}$ is fixed, the fitting curve is $y_{4}=-3148.1 \times x+109336$. $R^{2}=0.9678$. Note that $\eta_{1}$ and $\eta_{2}$ are negatively correlated with the radial stress in excavation surface. The slope of $y_{3}$ is greater than $y_{4}$, which indicates that the effect of $\eta_{1}$ on the excavation surface radial stress is also larger than the effect of $\eta_{2}$. Therefore, the magnitude of the radial stress in the excavation surface of the tunnel is equivalent to the supporting force of the rock mass in the coupling model, and the greater the support force is, the better the support effect. The smaller $\eta_{1}$ or $\eta_{2}$ is, the better the support effect in the excavation moment. Figure $7 \mathrm{c}$ shows the evolution of the radial stress of the reinforced zone monitoring point $\rho=4 \mathrm{~m}$ over time (influence of $\eta_{1}$ and $\sigma_{0}$ ). The absolute value of radial stress gradually decreases over time because the stress of the rock mass is gradually released 
over time. When the parameters $\eta_{1}$ and $\eta_{2}$ are constant, a larger $\sigma_{0}$ yields a greater absolute value of the initial and convergence values. When the parameter $\eta_{2}$ is fixed, a larger $\eta_{1}$ produces a smaller absolute value of the initial radial stress. The radial stress converges to a fixed value over time, and the fixed value is independent of $\eta_{1}$. A smaller $\eta_{1}$ produces a larger change rate. Figure $7 \mathrm{~d}$ shows the evolution of the radial stress over time for the reinforced zone monitoring point $\rho=4 \mathrm{~m}$ (influence of $\eta_{2}$ and $\sigma_{0}$ ). The absolute value of radial stress gradually decreases over time; when the parameters $\eta_{1}$ and $\eta_{2}$ are fixed, a greater value of $\sigma_{0}$ yields a higher absolute value of initial radial stress and convergence value. When $\eta_{1}$ is constant, a smaller $\eta_{2}$ produces a larger absolute value of the initial and convergence values. Thus, the smaller is the $\eta_{2}$, the better is the support effect. $\eta_{2}$ does not have a significant effect on the rate of change, which remains fairly constant.

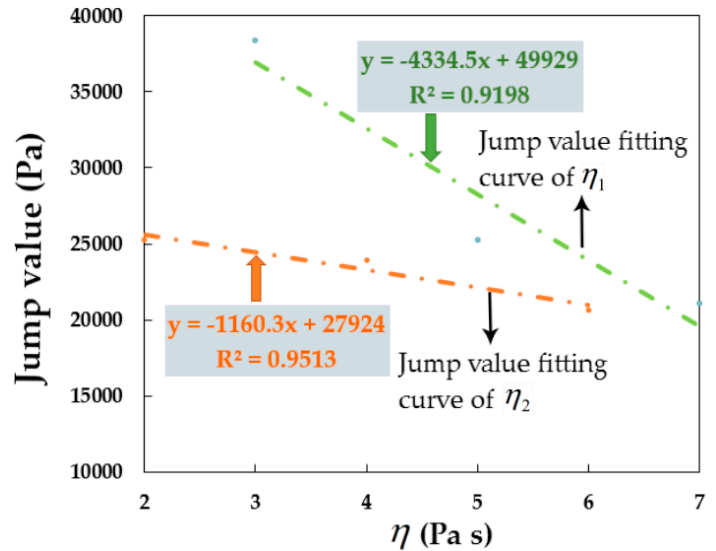

(a)

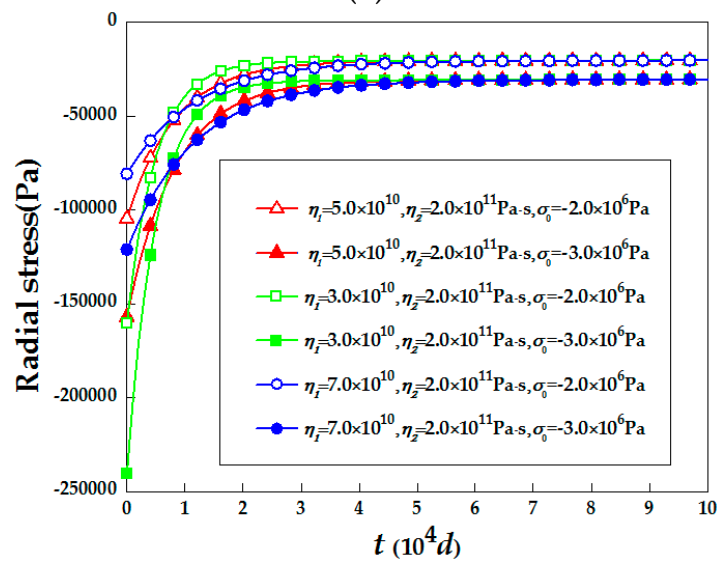

(c)

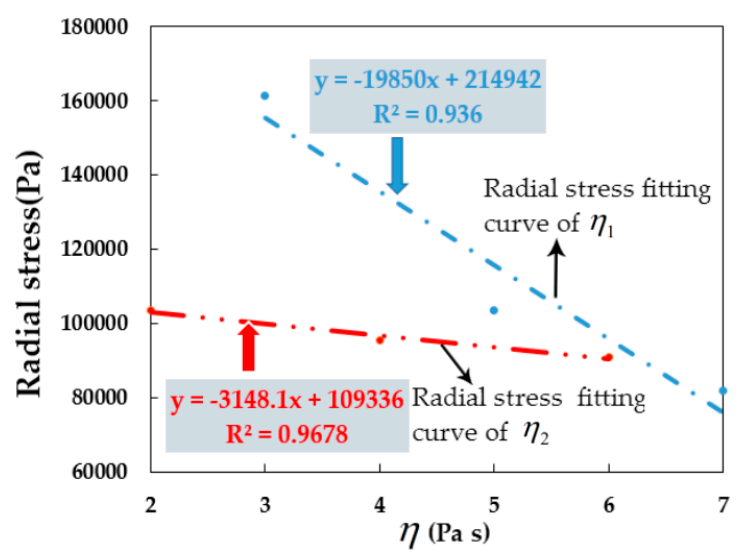

(b)

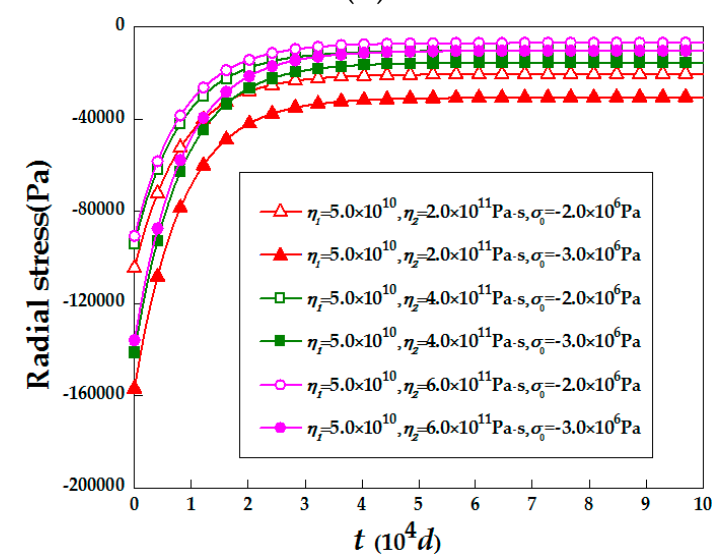

(d)

Figure 7. Mechanical states in cases 1-7: (a) influence of $\eta_{1}$ and $\eta_{2}$ on the radial stress jump value and its fitting; (b) influence of $\eta_{1}$ and $\eta_{2}$ on the excavation surface radial stress and its fitting. (c,d) reinforced zone monitoring points $\rho=4 \mathrm{~m}$ (influences $\eta_{1}, \sigma_{0}$, and $\eta_{2}, \sigma_{0}$ ).

\subsection{Tangential Stress Changes over Time}

The tangential stress at the monitoring point $\rho=6 \mathrm{~m}$ of the reinforced zone is shown in Figure $8 \mathrm{a}, \mathrm{b}$. Figure 8a shows the influence of $\eta_{2}$ on the tangential stress in the reinforced zone over time. The tangential stress gradually decreases over time and then converges to a stable value. When $\eta_{1}$ is fixed, a larger $\eta_{2}$ generates a larger initial and stable values of the tangential stress. Figure $8 \mathrm{~b}$ shows the influence of $\eta_{1}$ on the reinforced zone tangential stress over time. The tangential stress also decreases over time and finally converges to a stable value. The constant value is independent of $\eta_{1}$, and a smaller $\eta_{1}$ yields a smaller initial value but a larger change rate. Figure $8 \mathrm{c}$ shows the influence of $\eta_{2}$ on the tangential stress of the original zone over time: $\eta_{1}$ influences not only the initial value but also 
the stable value; a smaller $\eta_{2}$ yields greater initial and stable values of the tangential stress. Figure $8 \mathrm{~d}$ shows the influence of $\eta_{1}$ on the tangential stress in the original zone over time. The tangential stress also decreases over time, and $\eta_{1}$ influences only the initial value. The tangential stress finally converges to a certain value. The constant value is independent of $\eta_{1}$, and a smaller $\eta_{1}$ produces not only a greater initial value but also a larger change rate.

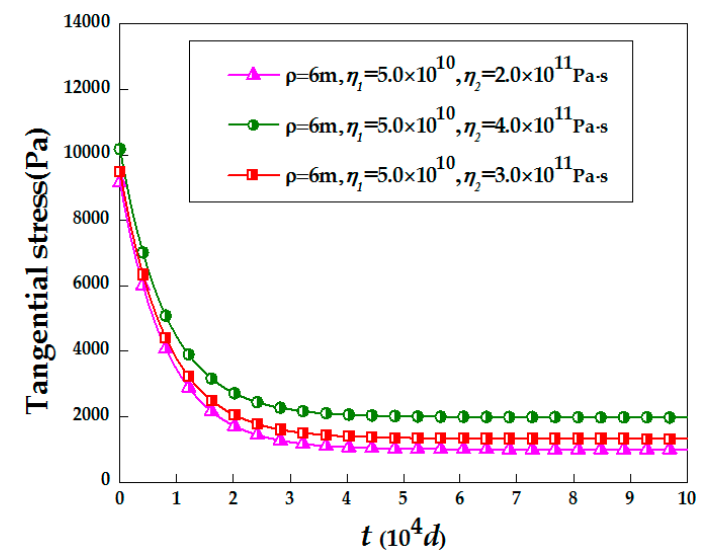

(a)

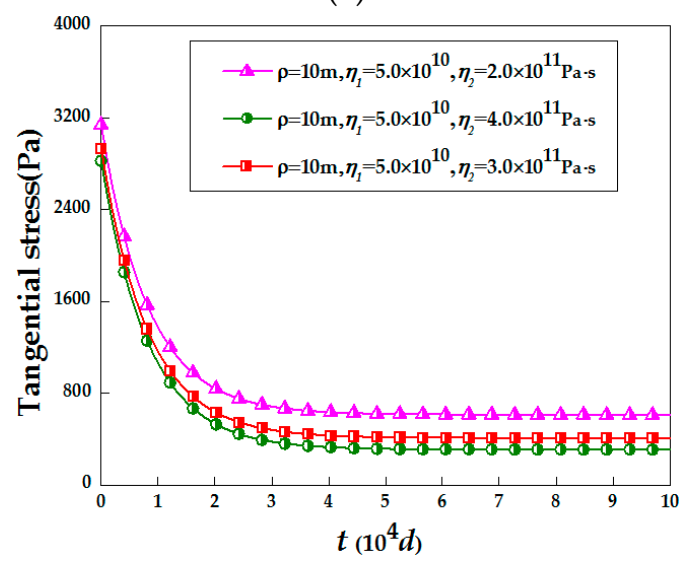

(c)

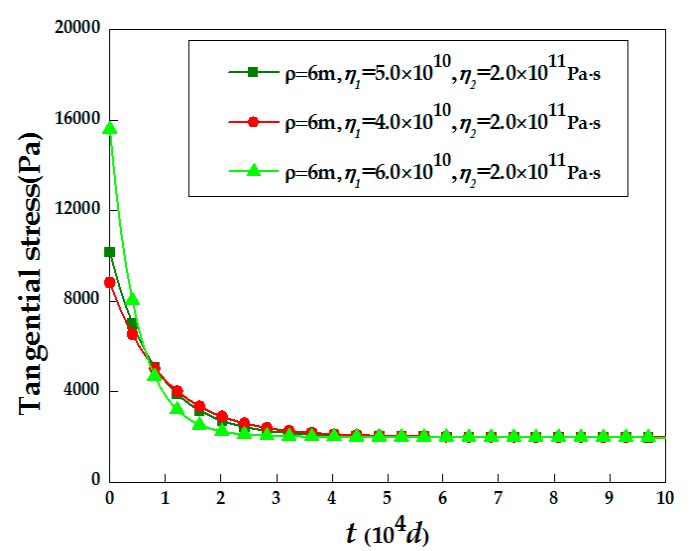

(b)

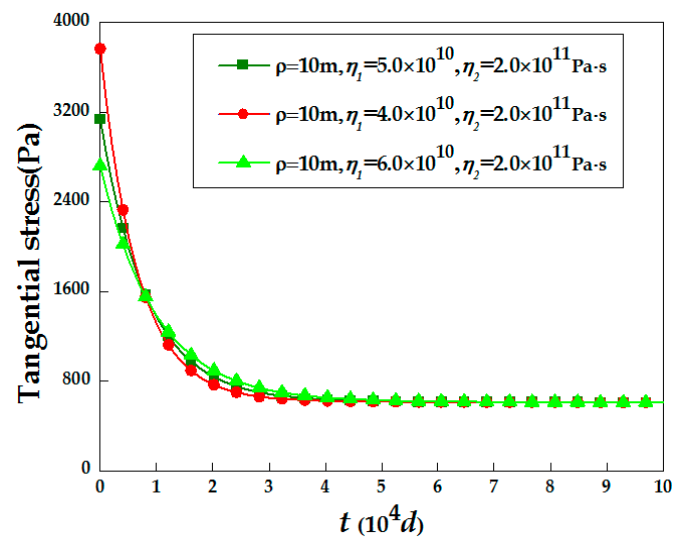

(d)

Figure 8. Evolution of the tangential stress over time: $(\mathbf{a}, \mathbf{b})$ reinforced zone monitoring point $\rho=6 \mathrm{~m}$; $(\mathbf{c}, \mathbf{d})$ original zone monitoring point $\rho=10 \mathrm{~m}$.

\subsection{Displacement Evolution over Time}

Figure 9a shows the displacement of the rock mass along the radial distance when the time is zero. When the radial distance increases, the displacement exponentially decreases and converges to zero along the depth of the rock mass. In the moment of excavation, when $\eta_{2}$ is fixed, a smaller $\eta_{1}$ causes a larger displacement at any position. If $\eta_{1}$ is fixed, a smaller $\eta_{2}$ yields a larger displacement. Figure $9 \mathrm{~b}$ shows the displacement when $t=4 \mathrm{~d}$ along the radial distance. The amount of displacement significantly changes from the excavation moment. Figure $9 \mathrm{c}$ shows the displacement evolution rule of $\rho=7 \mathrm{~m}$ over time, the displacement gradually increases and exponentially converges to a fixed value. A smaller $\eta_{1}$ produces larger absolute convergence values. A smaller $\eta_{2}$ yields larger absolute convergence values. Therefore, important support measures should be taken when $\eta_{1}$ or $\eta_{2}$ is small. 


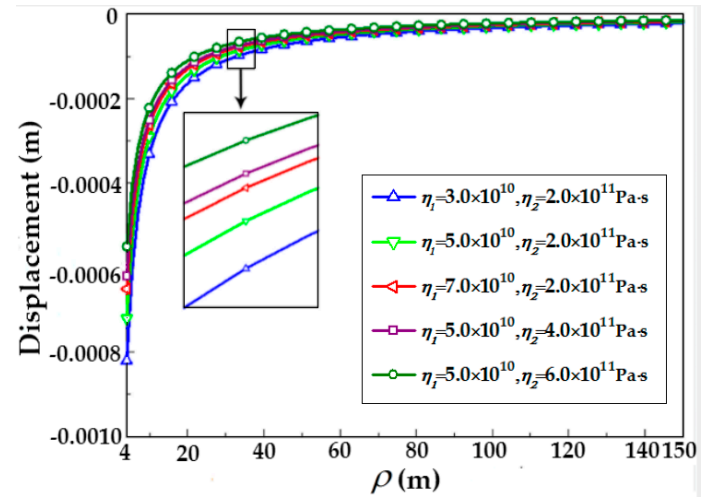

(a)

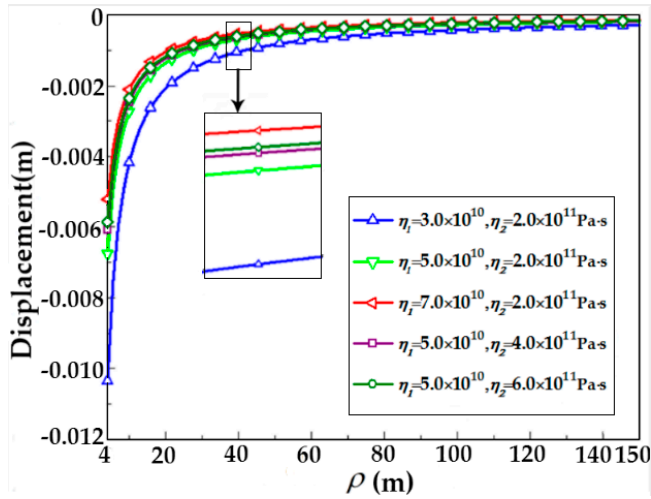

(b)

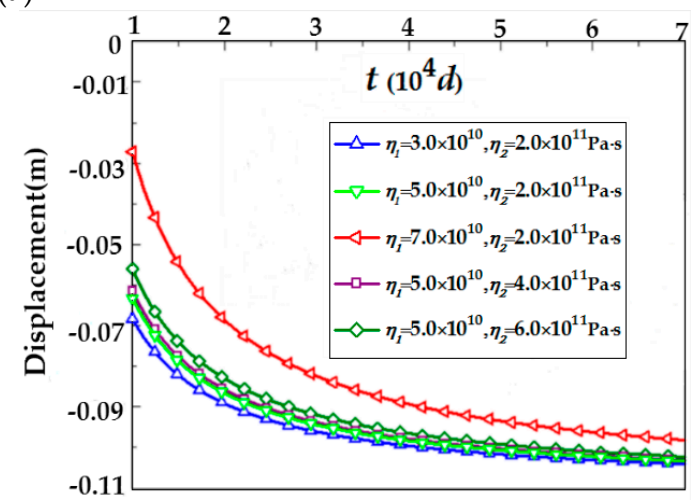

(c)

Figure 9. Deformation law of the rock mass: (a) displacement law of the excavation moment along the radial distance; (b) displacement law of $t=4 \mathrm{~d}$ along the radial distance; (c) displacement evolution curve of $\rho=7 \mathrm{~m}$.

\section{Conclusions}

During tunnel excavation, the stresses and deformation of rock mass and the axial force of rockbolt will change over time. This paper established a rheological model of the rock mass supported with DMFC rockbolts. The main findings can be summarized as follows:

(1) The axial force of DMFC rockbolts are positively correlated with the support force at the excavation face in a tunnel, and the greater the convergence value of the axial force is, the better the support effect. In addition, the greater the pre-tension of rockbolt, the better the reinforcement effect, however, when the pre-tension is too large, the rock bolt support effect will not increase significantly.

(2) The $\eta_{1}$ of the three-dimensional Burgers model influences the early support effect, $\eta_{2}$ of three-dimensional Burgers model affects both the early and the ultimate reinforcement effect. In addition, there is a significant negative correlation between rock mass displacement and $\eta_{1}$ or $\eta_{2}$. Therefore, important support measures should be taken when $\eta_{1}$ or $\eta_{2}$ is small.

(3) In this paper, the interaction model elastic solutions were solved based on the distributed force model. However, the axial force of the rockbolt is similar to the concentrated force to rock mass (Bobet 2006), Hence, a more suitable theoretical model should be explored to solve the coupling model in future.

(4) Continuously Mechanically Coupled (CMC) rockbolts applications are more extensive than DMFC rockbolts, the reasonable and simplified method for the theoretical model of CMC rockbolts can be further studied based on this model, which lays a foundation of the preliminary research for solving the theoretical model of CMC rockbolts. 
Author Contributions: All the authors contributed to publishing this paper. W.H. and G.W. contributed to the formulation of the overarching research goals and aims; C.L. contributed to the theoretical formula derivation of the model; H.L. and K.W. provided language and pictures supports.

Funding: This research was funded by National Natural Science Foundation of China (No. 51479108).

Conflicts of Interest: The authors declare no conflicts of interest.

\section{Nomenclature}

$A_{b}$

$L$

$\rho$

$r$

$T$

$P_{0}$

$k$

$\sigma_{\rho 1}$

$\sigma_{\theta 1}$

$u_{\rho 1}$

$\sigma_{\rho 1 s}$

$\sigma_{\theta 1 s}$

$u_{\rho 1 s}$

$S_{\theta}$

$\eta_{b}$

$\eta_{2}$

$\Delta x$

$G_{1}$

$t$

$S_{i j}$

$Q_{b}(D), P_{b}(D)$

$P^{\prime}(D), P^{\prime \prime}(D)$

$Q^{\prime}(D), Q^{\prime \prime}(D)$

$E_{r}$

$E_{b}$

$\theta$

$\sigma_{0}$

$\mu$

$P_{\rho}$

$R$

$\sigma_{\rho 2}$

$\sigma_{\theta 2}$

$u_{\rho 2}$

$\sigma_{\rho 2 s}$

$\sigma_{\theta 2 s}$

$u_{\rho 2 s}$

$S_{z}$

$\eta_{1}$

$\Delta L$

$G_{0}$

K

$\sigma_{i j}$

$e_{i j}$

${\overline{P_{b K}}}^{\prime}(s),{\overline{Q_{b K}}}^{\prime}(s)$

$\bar{P}^{\prime}(s), \bar{Q}^{\prime}(s)$

$\bar{P}^{\prime \prime}(s), \bar{Q}^{\prime \prime}(s)$
Area of the rockbolt cross-section

Length of rockbolt free part

Radial coordinate

Radius of tunnel

Axial force of the rockbolt bolt

Support force in tunnel opening

Stiff of the support system

Radial stress in the reinforced zone

Tangential stress in the reinforced zone

Displacement in the reinforced zone

Radial stress of the reinforced zone in Laplace

Tangential stress of the reinforced zone in Laplace

Displacement of the reinforced zone in Laplace

Rockbolt spacing in the tangential direction

Viscosity coefficient of the rock bolt

Viscosity coefficient of the second creep stage

Pre-tension length of the rockbolt

Viscoelastic shear modulus of rock mass

Time

Partial stress tensor

Operator functions of the Kelvin model

Operator function of rock mass viscoelastic constitutive model

Deformation modulus of the rock mass

Deformation modulus of the rockbolt

Circumferential angle

Initial stress

Poisson's ratio of rock mass

Reinforcement force

Radius of the reinforced rock zone

Radial stress in the original zone

Tangential stress in the original zone

Displacement in the original zone

Radial stress of the original zone in Laplace

Tangential stress of the original zone in Laplace

Displacement of the original zone in Laplace

Rockbolt spacing in the longitudinal direction

Viscosity coefficient of the first creep stage

Deformation of rockbolt in the axial direction

Elastic shear modulus of the rock mass

Elastic bulk modulus of the rock mass

Stress tensor

Partial strain tensor

Operator functions of the Kelvin model in Laplace space

Operator function of rock mass viscoelastic constitutive model after Laplace transformation 


\section{Appendix A}

The analytical solutions of the interaction model with pre-tension in Laplace space are shown below. The radial stress of the reinforced zone $(r<\rho<R)$ in Laplace is expressed as follows:

$$
\sigma_{\rho 1 s}=\frac{-R\left(\begin{array}{c}
\left(-A_{b} E_{b} b \sigma_{0} r^{4} a c+\left(\frac{2}{3} L c T_{0}+a\left(A_{b} E_{b} R \sigma_{0}+2 K L T_{0}\right)\right) b c r^{3}+\left(\frac { 8 } { 3 } L R \left(E_{b} S_{z} S_{\theta} \sigma_{0}\right.\right.\right. \\
\left.\left.-b T_{0}\right) c^{2}+\frac{7}{3}\left(\left(A_{b} E_{b} \sigma_{0} \rho^{2}-\frac{6}{7} T_{0} L R K\right) b+\frac{6}{7} E_{b} \sigma_{0} d R K\right) a c+A_{b} E_{b} a^{2} K b \rho^{2} \sigma_{0}\right) r^{2} \\
\left.-\rho^{2}\left(\frac{2}{3} L c^{2} T_{0}+\frac{7}{3}\left(A_{b} E_{b} \sigma_{0} R+\frac{6}{7} T_{0} L K\right) a c+A_{b} E_{b} a^{2} K R \sigma_{0}\right) b r-2\left(a K+\frac{4}{3} c\right) \rho^{2} S_{\theta} L S_{z}\right)
\end{array}\right)}{\rho^{2}\left(A_{b} b a\left(a K+\frac{1}{3} c\right) r^{3}-2\left(a K+\frac{4}{3} c\right) a b A_{b} R r^{2}+A_{b} b R^{2} a\left(a K+\frac{7}{3} c\right) r+2\left(a K+\frac{4}{3} c\right) S_{\theta} R^{2} c L S_{z}\right) E_{b}}
$$

The radial stress of the original zone $(\rho>R)$ in Laplace is expressed as follows:

$$
\sigma_{\rho 2 s}=\frac{\frac{1}{3}\left(\begin{array}{c}
-3 b r c\left(A_{b} E_{b} a r \sigma_{0}+2 L c T_{0}\right) R^{3}+\left(-6 c\left(a K+\frac{4}{3} c\right) L\left(E_{b} S_{z} S_{\theta} \sigma_{0}-b T_{0}\right) r^{2}+3 \rho^{2} \sigma_{0}(a K\right. \\
\left.\left.+\frac{7}{3} c\right) A_{b} E_{b} r+6 c \rho^{2}\left(a K+\frac{4}{3} c\right) S_{z} S_{\theta} \sigma_{0} L E_{b}\right) R^{2}+3 r^{2}\left(A_{b} E_{b} \sigma_{0} r^{2}-2 c T_{0} L\left(a K+\frac{1}{3} c\right) r\right. \\
\left.-2 \rho^{2}\left(a K+\frac{4}{3} b\right) a \sigma_{0} A_{b} E_{b}\right) b R+3 r^{3} \rho^{2} a \sigma_{0} b E_{b}\left(a K+\frac{1}{3} c\right) A_{b}
\end{array}\right)}{\left(\rho^{2}\left(\left(A_{b} b a\left(a K+\frac{7}{3} c\right) r+2 c\left(a K+\frac{4}{3} c\right) S_{z} S_{\theta} L\right) R^{2}-2 r^{2}\left(a+\frac{4}{3} c\right) A_{b}+A_{b} b r^{3} a\left(a K+\frac{1}{3} c\right) E_{b}\right)\right.}
$$

The tangential stress of the reinforced zone $(r<\rho<R)$ in Laplace is expressed as follows:

$$
\sigma_{\theta 1 s}=\frac{-\left(\begin{array}{c}
R\left(A_{b} E_{b} b \sigma_{0} r^{4} a c+c b\left(\frac{2}{3} L c T_{0}+a\left(A_{b} E_{b} R \sigma_{0}+2 K L T_{0}\right)\right) r^{3}+\left(-\frac{8}{3} L R\left(E_{b} S_{z} S_{\theta}-b T_{0}\right) c^{2}\right.\right. \\
\left.-\frac{7}{3} a\left(\left(A_{b} E_{b} \sigma_{0} \rho^{2}-\frac{6}{7} T_{0} L R K\right) b+\frac{6}{7} E_{b} S_{z} S_{\theta} L R K\right) c-A_{b} E_{b} a^{2} K b \rho^{2} \sigma_{0}\right) r^{2}+b\left(\frac{2}{3} L c^{2} T_{0}\right. \\
\left.\left.+\frac{7}{3} a\left(A_{b} E_{b} \sigma_{0} R+\frac{6}{7} T_{0} L K\right) c+A_{b} E_{b} a^{2} K R \sigma_{0}\right) \rho^{2} r+2 c E_{b} R\left(a K+\frac{4}{3} c\right) L S_{\theta} S_{z} \sigma_{0}\right)
\end{array}\right)}{E_{b} \rho^{2}\left(A b a\left(a K+\frac{1}{3} c\right) r^{3}-2 A b R\left(a K+\frac{4}{3} c\right) r^{2}+A R^{2} a\left(a+\frac{7}{3} c\right) r+2 R^{2}\left(a K+\frac{4}{3} c\right) L S_{\theta} S_{z}\right)}
$$

The tangential stress of the original zone $(\rho>R)$ in Laplace is expressed as follows:

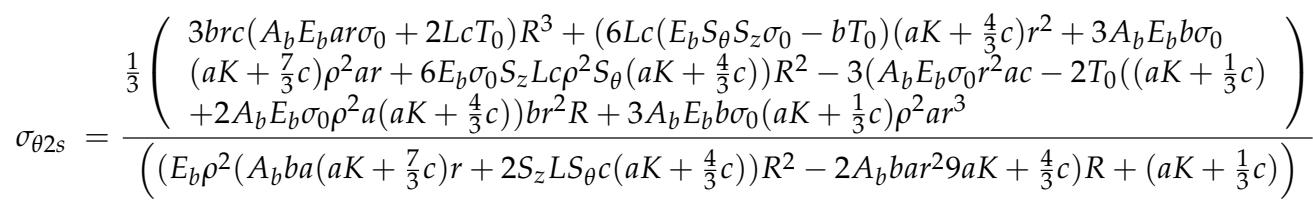

The displacement of the reinforced zone $(r<\rho<R)$ in Laplace is expressed as follows:

$$
u_{\rho 1 s}=\frac{\frac{1}{2}\left(\begin{array}{c}
\left(A_{b} E_{b} a b R r^{3} \sigma_{0}+b\left(\sigma_{0} a R^{2} A_{b} E_{b}+2\left(a K+\frac{1}{3} c\right) T_{0} L R-a \rho^{2} \sigma_{0} A_{b} E_{b}\right) r^{2}\right. \\
+\left(2\left(a K+\frac{4}{3} c\right)\left(E_{b} S_{z} S_{\theta} \sigma_{0}-b T_{0}\right) L R+A_{b} E_{b} a b \rho^{2} \sigma_{0}\right) R r-2 L c b R \rho^{2} T_{0} a r
\end{array}\right)}{\left(E_{b} \rho\left(A_{b} b a\left(a K+\frac{1}{3} c\right) r^{3}-2\left(a K+\frac{4}{3} c\right) a A_{b} b R r^{2}+A_{b} b R^{2} a\left(a K+\frac{7}{3} c\right) r+2\left(a K+\frac{4}{3} c\right) L S_{z} S_{\theta}\right)\right.}
$$

The displacement of the original zone $(\rho>R)$ in Laplace is expressed as follows:

$$
u_{\rho 2 s}=\frac{\frac{1}{2}\left(\begin{array}{c}
\left(r a R\left(-A_{b} E_{b} a b r^{3} \sigma_{0}+2 T_{0} L b\right)\left(a K+\frac{1}{3} c\right) r^{2}+\left(\left(\left(A_{b} E_{b} R \sigma_{0}-2 R K L T_{0}\right) a\right.\right.\right. \\
\left.\left.\left.-\frac{8}{3} L c T_{0}\right) b+2 S_{\theta} S_{z} \sigma_{0} L E_{b}\left(a K+\frac{4}{3} c\right)\right) R r+2 L c b R^{2} T_{0}\right)
\end{array}\right)}{\left(\left(A_{b} b a\left(a K+\frac{1}{3} c\right) r^{3}-2 a b A_{b}\left(a K+\frac{4}{3} c\right) R r^{2}+A_{b} b R^{2} a\left(a K+\frac{7}{3} c\right) r+2 S_{\theta} S_{z} L\left(a K+\frac{4}{3} c\right) R^{2}\right)\right)}
$$

The axial force of tensioned rockbolt in Laplace is expressed as follows:

$$
T=\frac{1}{2\left(1+\frac{\eta_{b} s}{E_{b}}\right) L}\left[\begin{array}{l}
\begin{array}{l}
\left(a r \left(-E_{b} A_{b} a b r^{3} \sigma_{0}+2 T_{0} L b\left(K a+\frac{1}{3} c\right) r^{2}+\left(\left(\left(E_{b} A_{b} R \sigma_{0}-2 K L T_{0}\right) a-\frac{8}{3} L T_{0} c\right) b+2 L S_{\theta} S_{z}\right.\right.\right. \\
\left.\left.\left.\left(a K+\frac{4}{3} c\right)\right) R r+2 L R^{2} T_{0} b c\right)\right)
\end{array} \\
\begin{array}{l}
\left(\left(A_{b} b a r^{3}\left(K a+\frac{1}{3} c\right)-2 A_{b} R a b r^{2}\left(K a+\frac{4}{3} c\right)+A_{b} a b r R^{2}\left(K a+\frac{7}{3} c\right)+2 L S_{z} S_{\theta} c\left(E_{b} R^{2}\left(K a+\frac{4}{3} c\right)\right)\right.\right. \\
\left(E_{b} a b \sigma_{0}+2 b\left(\left(K a+\frac{1}{3} c\right) T_{0} L R r^{2}+\left(2\left(K a+\frac{4}{3} c\right)\left(E_{b} S_{z} S_{\theta} \sigma_{0}-b T_{0}\right) L R+E_{b} A_{b} R^{2}\right)\right.\right.
\end{array} \\
-\frac{\left.\left.R r-2 L T_{0} R^{3} b c\right) a r\right)}{\left.\left.\left(E_{b} R\left(A_{b} b a\left(a K+\frac{1}{3} c\right) r^{3}-2 a b A_{b}\left(K a+\frac{4}{3} c\right) R r^{2}+a b A_{b}\left(K a+\frac{7}{3} c\right)+2 L S_{z} S_{\theta}\left(K a+\frac{4}{3} c\right) R^{2}\right)\right)\right) s\right)}
\end{array}\right]
$$

where

$$
\begin{gathered}
a=\bar{P}^{\prime}(s)=1+\left(\frac{\eta_{2}}{G_{0}}+\frac{\eta_{1}+\eta_{2}}{G_{1}}\right) s+\frac{\eta_{1} \eta_{2} s^{2}}{G_{0} G_{1}} \\
b={\overline{Q_{b K}}}^{\prime}(s)=s \eta_{b}+E_{b}
\end{gathered}
$$




$$
c=\bar{Q}^{\prime}(s)=\eta_{2} s+\frac{\eta_{1} \eta_{2} s^{2}}{G_{1}}
$$

\section{References}

1. Kovári, K. History of the sprayed concrete lining method-Part I. Milestones up to the 1960s. Tunn. Undergr. Space Technol. 1992, 18, 57-69. [CrossRef]

2. Cai, Y.; Tetsuro, E.; Jiang, Y.J. A rock bolt and rock mass interaction model. Int. J. Rock Mech. Min. Sci. 2004, 41, 1055-1067. [CrossRef]

3. Sun, J. Rock rheological mechanics and its advance in engineering applications. Chin. J. Rock Mech. Eng. 2007, 26, 1081-1106.

4. Phienwej, N.; Thakur, P.K.; Cording, E.J. Time-dependent response of tunnels considering creep effect. Int. J. Geomech. 2007, 7, 296-306. [CrossRef]

5. Goodman, R. Introduction to Rock Mechanics; Wiley: New York, NY, USA, 1989.

6. Nomikos, P.; Rahmannejad, R.; Sofianos, A. Supported axisymmetric tunnels within linear viscoelastic Burgers rocks. Rock Mech. Rock Eng. 2011, 44, 553-564. [CrossRef]

7. Ladanyi, B.; Gill, D.E. Tunnel lining design in creeping rocks. Int. J. Rock Mech. Min. Sci. Geomech. Abstr. 1985, 22, A17. [CrossRef]

8. Sulem, J.; Panet, M.; Guenot, A. An analytical solution for time-dependent displacements in circular tunnel. Int. J. Rock Mech. Min. Sci. Geomech. Abstr. 1987, 24, 155-164. [CrossRef]

9. Ladanyi, B. Time-dependent response of rock around tunnels. In Comprehensive Rock Engineering; Hudson, J., Ed.; Pergamon: London, UK, 1993; Volume 2, pp. 77-112.

10. Panet, M. Understanding deformations in tunnels. In Comprehensive Rock Engineering; Hudson, J., Ed.; Pergamon: London, UK, 1993; Volume 1, pp. 663-690.

11. Ghaboussi, J.; Gioda, G. On the time-dependent effects in advancing tunnels. Int. J. Numer. Methods Geomech. 1977, 1, 249-269. [CrossRef]

12. Gioda, G. A finite element solution of non-linear creep problems in rock. Int. J. Rock Mech. Min. Sci. Geomech. Abstr. 1981, 18, 35-46. [CrossRef]

13. Peila, D.; Oreste, P.; Rabajuli, G.; Trabucco, E. The pre-tunnel method, a new Italian technology for full-face tunnel excavation: A numerical approach to design. Tunn. Undergr. Space Technol. 1995, 10, 367-374. [CrossRef]

14. Li, J.J.; Zheng, B.L.; Xu, C.Y. Numerical analyses of creep behavior for prestressed anchor rods. Chin. Q. Mech. 2007, 28, 124-128.

15. Wang, G.; Liu, C.Z.; Jiang, Y.J.; Wu, X.Z.; Wang, S.G. Rheological Model of DMFC Rockbolt and Rockmass in a Circular Tunnel. Rock Mech. Rock Eng. 2015, 48, 2319-2357. [CrossRef]

16. Sharifzadeh, M.; Tarifard, A.; Moridi, M.A. Time-dependent behavior of tunnel lining in weak rock mass based on displacement back analysis method. Tunn. Undergr. Space Technol. 2013, 38, 348-356. [CrossRef]

17. Labiouse, V. Ground response curves for rock excavations supported by ungrouted tensioned rockbolts. Rock Mech. Rock Eng. 1996, 29, 19-38. [CrossRef]

18. Bobet, A. A simple method for analysis of point anchored rockbolts in circular tunnels in elastic ground. Rock Mech. Rock Eng. 2006, 39, 315-338. [CrossRef]

19. Carranza-Torres, C.; Fairhurst, C. Application of the convergence-confinement method of tunnel design to rock masses that satisfy the Hoek-Brown failure criterion. Tunn. Undergr. Space Technol. 2000, 15, 187-213. [CrossRef]

20. Bobet, A.; Einstein, H.H. Tunnel reinforcement with rockbolts. Tunn. Undergr. Space Technol. 2011, 26, 100-123. [CrossRef]

21. Wang, Z.Y.; Li, Y.P. Rock Rheology Theory and Numerical Simulation; Science Press: Beijing, China, 2008. 